\title{
ESTIMASI INTENSITAS UPWELLING PANTAI DARI SATELIT AQUAMODIS DI PERAIRAN SELATAN JAWA DAN BARAT SUMATERA
}

\author{
ESTIMATION OF COASTAL UPWELLING INDEX USING AQUA-MODIS SATELLITE \\ CENSOR IN SOUTH JAVA AND WEST SUMATERA
}

\author{
Dortje Thedora Silubun ${ }^{1}$, Jonson Lumban Gaol'2, Yuli Naulita ${ }^{2}$ \\ ${ }^{1}$ Program Studi Teknologi Kelautan, Sekolah Pascasarjana \\ ${ }^{2}$ Departemen Ilmu dan Teknologi Kelautan \\ Fakulltas Perikanan dan Ilmu Kelautan, Institut Pertanian Bogor \\ Korespondensi : nona.silubun@gmail.com
}

\begin{abstract}
Monsoonal upwelling generally occurred along the coasts of South Java to Western Sumatera. The aimed of this study was to estimate the upwelling intensity derived from sea surface temperature (SST) and chlorophyll-a. SST and chlorophyll-a data was obtained from $3^{\text {rd }}$ level of Aqua-MODIS satellite censor, and wind data derived from Quikscat satellite censor on July 2002 to June 2011. Upwelling index derived from coastal upwelling index (CUIx) formula. Statistical analysis was used to describe the relationship of SST and chlorophyll-a to CUIx. The result of this study show that the occurrence of upwelling was in east monsoon temporally, the range of SST is about $25.10-27.30^{\circ} \mathrm{C}$ and chlorophyll-a is about 0.30 $-0.67 \mathrm{mg} \mathrm{m}^{-3}$. However in 2006 the anomaly of upwelling intensity coincide perfectly with the descend of SST to 24.98 ${ }^{\circ} \mathrm{C}$ (Sout Java) and $25.97{ }^{\circ} \mathrm{C}$ (West Sumatera), meanwhile the concentration of chlorophyll-a is increase to $1.3 \mathrm{mg} \mathrm{m}^{-3}$ (West Sumatra) and $3.71 \mathrm{mg} \mathrm{m}^{-3}$ (South Java). Statistical analysis show that the SST give a strong relationship between CUIx and SST $(r=0.84)$ in West Sumatera. Meanwhile in South Java, both of those parameters (SST and Chlorophyll-a) gives the strong relationship to CUIx respectively $(r=0.86$ and $r=0.81)$.
\end{abstract}

Keywords: chlorophyll-a, coastal Upwelling Index, sea surface temperature, Western Sumatera

\begin{abstract}
ABSTRAK
Upwelling musiman pada umumnya terjadi di sepanjang selatan jawa hingga barat sumatra. Penelitian ini bertujuan untuk mengestimasi intensitas upwelling dari data SPL dan konsentrasi klorofil-a dari sensor satelit. Data SPL dan Klorofil-a yang digunakan adalah data satelit Aqua-MODIS level-3 dan data angin dari satelit Quikescat pada bulan Juli 2002 sampai Juni 2011. Indeks upwelling diperoleh dengan formula Coastal Upwelling Index (CUIx). Analisis statistik digunakan untuk melihat hubungan antara SPL dan klorofil dengan CUIx. Hasil penelitian menunjukan bahwa secara temporal upwelling terjadi pada musim timur, dengan kisaran SPL $25.10-27.30{ }^{\circ} \mathrm{C}$ dan konsentrasi klorofil-a $0.30-0.67 \mathrm{mg} \mathrm{m}^{-3}$. Namun pada tahun 2006 terjadi anomali intensitas upwelling yang ditandai dengan SPL yang turun mencapai $24.98{ }^{\circ} \mathrm{C}($ Selatan Jawa) dan $25.97{ }^{\circ} \mathrm{C}$ (Barat Sumatera), konsentrasi klorofil-a meningkat $1.33 \mathrm{mg} \mathrm{m}^{-3}$ (Barat Sumatera) dan $3.71 \mathrm{mg} \mathrm{m}^{-3}$ (Selatan Jawa). Hasil analisis menunjukkan bahwa SPL memiliki hubungan yang sangat kuat dengan CUIx di Barat Sumatra $(r=0.84)$. Sementara di perairan selatan Jawa, kedua parameter (SPL dan klorofil-a) menunjukkan hubungan yang sangat kuat dengan CUIx ( $r=0.86$ yang untuk SPL dan $r=0.81$ untuk klorofil-a).
\end{abstract}

Kata kunci: coastal Upwelling Index, klorofil-a, sea surface temperature, barat Sumatera 


\section{PENDAHULUAN}

Upwelling adalah peristiwa naiknya massa air dari lapisan bawah ke permukaan perairan (Nontji 2007; Nybakken 1988). Proses upwelling disebabkan karena adanya pengaruh angin dan proses divergensi Ekman. Angin yang berhembus terus menerus dengan kecepatan penuh dalam waktu yang lama sejajar garis pantai mendorong massa air dan karena gaya coriolis, sebagai akibat pengaruh rotasi bumi, massa air bergerak menjauhi pantai. Di belahan bumi utara pembelokan mengarah ke kanan dari arah arus sedangkan pada belahan bumi selatan pembelokan mengarah ke kiri dari arah arus. Air permukaan yang bergerak menjauhi pantai akan diisi air yang dingin di bawahnya naik untuk mengisi kekosongan pada daerah permukaan (Wyrtki 1961; Bowden 1983; Pond dan Pichard 1983; Hutabarat dan Evans 1985; Mann dan Lazier 1993; Stewart 2002).

Daerah upwelling sangat menarik bagi para peneliti karena di daerah upwelling kesuburan perairan dan produktivitas primer tinggi sehingga produktivitas perikanan akan meningkat pula di perairan tersebut (Thurman 1991 vide Kunarso 2005). Oleh karena itu daerah upwelling sangat penting dalam dunia perikanan khususnya perikanan tangkap. Sekitar (90\%) hasil perikanan dunia dipanen dari sekitar 2-3\% luasan lautan, yang sebagian besarnya adalah daerah upwelling (Dahuri 1996; Nybakken 1988). Produktivitas rata-rata dari daerah upwelling adalah sekitar $300 \mathrm{gC} / \mathrm{cm}^{2} /$ tahun, dan dapat memproduksi ikan basah sebesar 12 x 105 ton/tahun. Fenomena upwelling ini sangat menarik untuk dikaji karena walaupun area terjadinya upwelling hanya sekitar (1\%) dari luas permukaan laut, namun mendukung 20\% lebih terhadap produktifitas perikanan dunia (Cushing 1971; Mann 2000).

Terjadinya upwelling menyebabkan suhu permukaan laut (SPL) rendah, salinitas tinggi, densitas tinggi, oksigen relatif rendah dan nutrien tinggi yang menyebabkan fitoplankton melimpah. Intensitas/kekuatan upwelling biasanya dihitung dengan menggunakan indeks upwelling yang dikembangkan oleh Bakun (1973). Paramater yang digunakan dalam indeks upwelling adalah kecepatan angin.

Beberapa penelitian di perairan Selatan Jawa sebelumnya telah dilakukan untuk mengkaji daerah upwelling. Penelitian diawali dengan penelitian berskala in situ yang dilakukan oleh Wyrtki (1961). Kemudian berlanjut dengan menggunakan data penginderaan jauh, Gaol (2003) menganalisis upwelling di Selatan Jawa dengan memetakan data penginderaan jauh. Tubalawony (2007) mengkaji upwelling dari kedalaman transpor Ekman. Inaku (2011) menganalisis pola sebaran dan perkembangan area upwelling di selatan perairan Selat Makasar. Pengaruh dari durasi dan intensitas upwelling terhadap produktifitas primer di perairan Indonesia dipengaruhi oleh fenomena El Nino, pada saat El Nino durasi upwelling lebih lama dan intensitas upwelling meningkat, sehingga menghasilkan produktivitas yang lebih tinggi dibandingkan tahun-tahun normal (Kemili 2012). Semua penelitian tersebut hanya mengkaji upwelling dari perubahan fisik, kimia dan biologi tanpa menghitung intensitas upwelling, sehingga dalam penelitian ini perlu dilakukan perhitungan untuk mengkaji kekuatan dari upwelling.

Perkembangan teknologi penginderaan jauh memberikan kemudahan untuk pemetaan sebaran SPL dan konsentrasi klorofil-a sehingga tersedia cukup banyak data baik secara spasial maupun temporal. Aqua-MODIS merupakan salah satu satelit yang dapat digunakan untuk memetakan sebaran SPL dan konsentrasi klorofil-a karena secara temporal datanya tersedia sampai saat ini. Ketersedian data ini yang dapat digunakan untuk mengkaji intensitas upwelling. Adapun tujuan dari penelitian ini untuk mengestimasi intensitas upwelling dari data SPL dan konsentrasi klorofil-a menggunakan satelit Aqua MODIS serta mengkaji variabilitas intensitas upwelling berdasarkan parameter SPL dan konsentrasi klorofil-a.

\section{METODE PENELITIAN}

Penelitian dilaksanakan pada perairan pantai barat Sumatera sampai selatan Jawa, koordinat $2{ }^{\circ} \mathrm{LS}-10^{\circ} \mathrm{LS}$ dan $98^{\circ} \mathrm{BT}-$ $115^{\circ} \mathrm{BT}$ (Gambar 1). Data yang digunakan adalah data SPL dan konsentrasi klorofil-a citra satelit Aqua-MODIS level-3 dengan resolusi spasial $0.05^{\circ} \times 0.05^{\circ}$ dan resolusi temporal bulanan dari bulan Juli 2002Juni 2011. Data vektor angin dari satelit Quickscat pada bulan Juli 2002-Juni 2011 yang diperoleh dari website National Oceanic and Atmospheric Administration (NOAA)-USA (http://las.pfeg.noaa.gov/OceanWatch/ oceanwatch/php). 
Pengolahan data menggunakan perangkat lunak Ferret 6.8 untuk menghasilkan pola sebaran SPL dan konsentrasi klorofil-a. Algoritma yang digunakan untuk mengestimasi SPL adalah algoritma Miami Pathfinder (2001), dan algoritma OC3M (Ocean Cholorophyll 3-band algoritm MODIS) O'Reilly et al. (2000) untuk konsentrasi klorofil-a.

Indeks Upwelling Pantai (UI) dihitung dengan beberapa tahap formula sebagai berikut : menggunakan data vektor angin untuk mendapatkan gesekan angin (wind stress) tiap komponen angin dengan menggunakan persamaan yang di kemukakan oleh Kutsuwada (1998):

$$
\begin{aligned}
\tau_{x} & =\rho C_{D} W u \\
\tau_{y} & =\rho C_{D} W v
\end{aligned}
$$

dimana :

$\tau_{x}=$ gesekan angin komponen sejajar pantai $\left(\mathrm{kg} \mathrm{det}^{-2} \mathrm{~m}^{-1}\right)$

$\tau_{\mathrm{y}}=$ Gesekan angin komponen menegak pantai $\left(\mathrm{kg} \mathrm{det}^{-2} \mathrm{~m}^{-1}\right)$

$C_{D}=$ koefisien Drag $=1.4 \times 10^{-3}$

$\rho=$ densitas udara $=1.3 \mathrm{~kg} \mathrm{~m}^{-3}$

$W=$ kecepatan angin $\left(\mathrm{m} \mathrm{det}^{-1}\right)$

$u=$ komponen kecepatan angin pada sumbu $\mathrm{x}\left(\mathrm{m} \operatorname{det}^{-1}\right)$

$v=$ komponen kecepatan angin pada sumbu $\mathrm{y}\left(\mathrm{m} \mathrm{det}{ }^{-1}\right)$

Untuk perairan Barat Sumatera, data vektor angin terlebih dahulu diubah menjadi komponen angin sejajar pantai (komponen $\mathrm{x}$ ) dan komponen angin menegak pantai (komponen y) menggunakan formula (Arfken, 1985):

$$
\begin{aligned}
& u_{n}=u_{0} \cos \varphi+v_{0} \sin \varphi \\
& v_{n}=-u_{0} \sin \varphi+v_{0} \cos \varphi
\end{aligned}
$$

dimana:

$u_{n}$ dan $v_{n}=$ komponen angin setelah dirotasi $u_{0}$ dan $v_{0}=$ komponen vektor angina

$\varphi=$ Sudut rotasi yang berlawanan arah jam dengan daratan disebelah kanannya

Indeks upwelling pantai kemudian dihitung dengan formula dikembangkan dari teori Ekman's (1905), perhitungan transport Ekman menggunakan persamaan
(Pond and Pickard 1983) :

$$
\mathrm{Mx}=\frac{\tau_{y}}{f}
$$

dimana :

$\mathrm{Mx}=$ Massa offshore transport ekman (kg $\operatorname{det}^{-2} \mathrm{~m}^{-1}$ )

$\tau_{y}=$ Gesekan angin komponen menegak pantai $\left(\mathrm{kg} \mathrm{det}^{-2} \mathrm{~m}^{-1}\right)$

$f=$ parameter coriolis $\left(\mathrm{rad} \mathrm{det}^{-1}\right)$

sedangkan

$$
\mathrm{f}=2 \Omega \sin \theta
$$

dimana :

$\Omega=$ Kecepatan rotasi bumi pada sumbu $=$ $7.29 \times 10^{-5} \mathrm{rad} \mathrm{det}^{-1}$

$\Theta=$ Lintang

Formula untuk mendapatkan indeks upwelling pantai (UI) menggunakan persamaan (Bakun 1973):

$\mathrm{UI}=\quad M x \frac{100 m \text { coastline }}{1025 \mathrm{~kg} / \mathrm{m}^{3}}\left(\frac{\frac{\mathrm{m}^{3}}{\mathrm{~s}}}{100} m\right.$ coastline $)$

dimana :

$M x=$ Massa offshore transport ekman (kg $\operatorname{det}^{-2} \mathrm{~m}^{-1}$ )

$\mathrm{UI}=$ Indeks Upwelling Pantai $\left(\mathrm{m}^{3} / \mathrm{s} / 100 \mathrm{~m}\right.$ coastline)

Dengan asumsi bahwa jika nilai transport ekman's negatif (ekman's transport offshore) maka Coastal Upwelling Index (CUIx) akan menunjukan terjadinya proses upwelling sebaliknya jika nilainya positif (ekman's transport onshore) maka yang terjadi adalah proses downwelling.

Hubungan antara CUIx dengan SPL dan konsentrasi klorofil-a dikaji dengan menggunakan analisis regresi dan korelasi dengan menggunakan persamaan $\mathrm{y}=\mathrm{a}+\mathrm{bx}$ dimana : $\mathrm{y}=$ CUIx ; $\mathrm{x}=$ SPL, konsentrasi klorofil-a. 


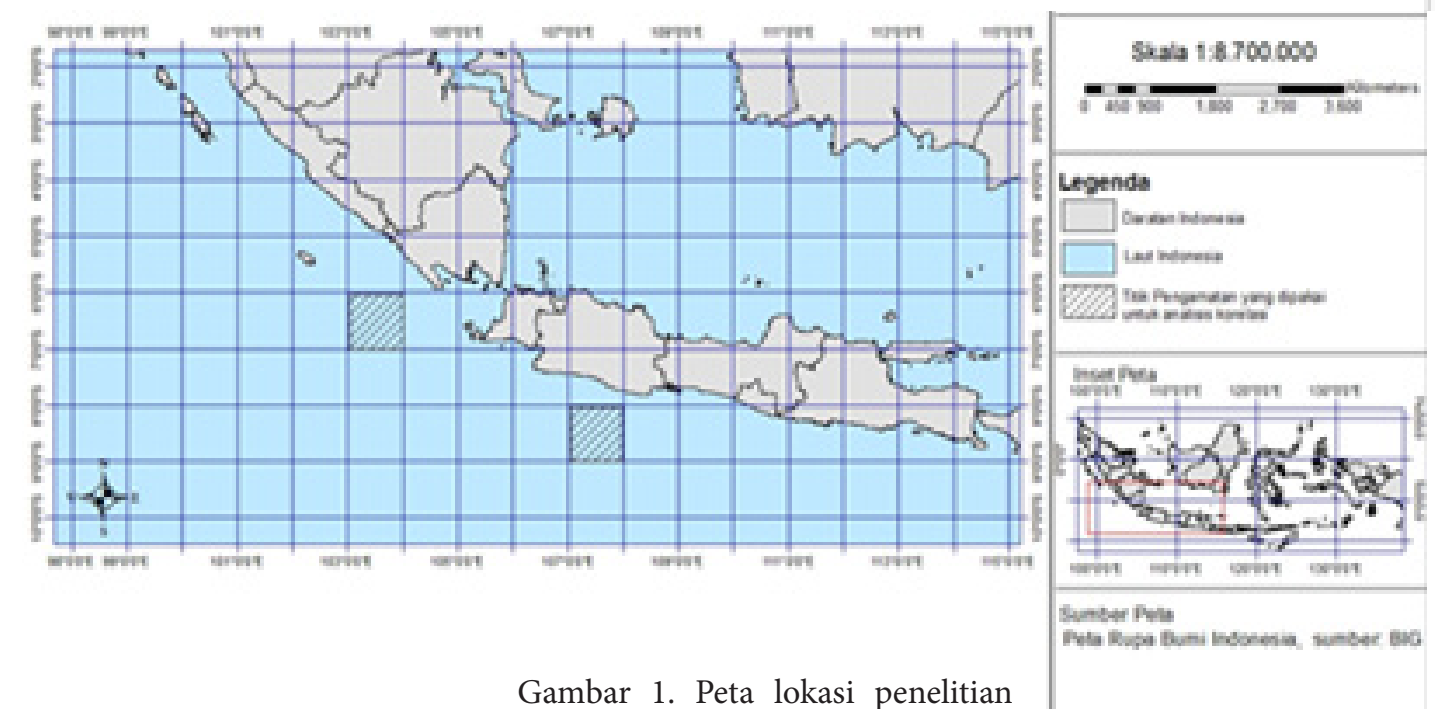

\section{HASIL DAN PEMBAHASAN}

\section{Intensitas upwelling pantai}

Gambar 2 memperlihatkan distribusi intensitas upwelling pantai secara spasial yang menunjukan adanya intensitas yang tinggi pada perairan barat selatan Jawa selama musim timur (Gambar 2 bagian atas). Intensitas upwelling umumnya terjadi pada musim timur dan peralihan II di perairan selatan Jawa dan barat Sumatera (Susanto et al. 2001). Adanya intensitas yang tinggi di bagian barat perairan selatan Jawa pada musim timur (bulan Agustus) karena adanya tiupan angin yang kuat. Susanto et al. (2001) mengatakan bahwa pada bulan Juli-Agustus di perairan selatan Jawa Barat (sekitar $105^{\circ} \mathrm{BT}$ ) bertiup angin muson tenggara. Pengaruh gesekan angin di perairan selatan Jawa pada musim timur semakin melemah ke arah timur selatan Jawa yang mengakibatkan intensitas upwelling juga semakin melemah.

Pada musim timur tiupan angin memiliki kekuatan yang lebih tinggi dari pada musim lainnya di perairan barat Sumatera (Tubalawony 2007). Sehingga berpengaruh juga pada intensitas upwelling di barat Sumatera. Kondisi yang berbeda terjadi pada musim barat (Gambar 2 bagian bawah) dimana tidak terlihat adanya intensitas upwelling di sepanjang perairan tersebut, walaupun hasil indeks menunjukkan adanya nilai negatif tetapi intensitasnya sangat rendah jika dibandingkan dengan musim timur.

Secara temporal intensitas upwelling terjadi pada musim timur dan peralihan I di perairan selatan Jawa sampai barat Sumatera (Gambar 3). Pada kondisi normal variabilitas upwelling menunjukan intensitas yang hampir sama, namun saat terjadinya anomali pada tahun 2006 intensitas upwelling pantai sangat tinggi. Hal ini yang diduga karena adanya pengaruh Indian Ocean Dipole Mode (IODM) positif yang kuat dimana terjadinya anomali tiupan angin muson tenggara yang intensitasnya jauh lebih tinggi dan berlangsung dalam periode yang jauh lebih panjang dari kondisi normalnya (Amri 2012). Pada saat IODM positif, terjadi kecenderungan anomali angin selatan di sepanjang perairan pantai Jawa hingga Sumatera dan angin timur di sepanjang ekuator (Gaol 2003). Intensitas upwelling yang rendah terjadi pada tahun 2010, hal ini berkaitan dengan pengaruh IODM negatif yang terjadi pada Samudera Hindia.

\section{Hubungan antara Indeks upwelling Pantai (CUIx) dengan SPL dan konsentrasi klorofil-a}

Gambar 4 menunjukkan hasil analisis antara SPL, klorofil-a dengan CUIx pada kedua titik pengamatan yang mewakili 
barat Sumatera dan Selatan Jawa (Gambar 1). Scatter plot memperlihatkan adanya hubungan yang linier antara SPL dan CUIx, sedangkan antara klorofil-a dengan CUIx menunjukan pola logaritmik. Hubungan antara SPL dengan CUIx di perairan Barat Sumatera ditunjukkan pada persamaan CUIx $=70.37 \mathrm{SPL}-2146.1 \quad(\mathrm{r}=0.74)$ dan perairan Selatan Jawa dengan persamaan CUIx = 30.71 SPL-954.64 $(r=0.79)$. Persamaan tersebut menunjukkan hubungan yang erat antara SPL dan CUIx pada kedua perairan tersebut. Hubungan antara klorofil-a dengan CUIx memiliki pola yang berbeda yaitu pola logaritma. Persamaan yang diperoleh untuk perairan barat Sumatera adalah $\mathrm{CUIx}=$ -120.4lon(Chl)-286.18 dengan koefisien korelasinya $(\mathrm{r}=0.64)$, sedangkan selatan Jawa CUIx $=-55.23 \ln (\mathrm{Chl})-159.06$ dengan koefisien korelasi $(\mathrm{r}=0.70)$. Dari nilai koefisien korelasinya maka dapat dikatakan bahwa konsentrasi klorofil-a pada barat Sumatera memiliki hubungan yang erat dengan CUIx, sedangkan perairan selatan Jawa memiliki hubungan yang lebih erat.

Berdasarkan hasil korelasi dan regresi diketahui bahwa parameter yang memiliki hubungan yang erat dengan CUIx adalah SPL yang ditunjukkan dengan nilai koefisien korelasi yang lebih besar jika dibandingkan dengan konsentrasi klorofil-a. Hal ini disebabkan karena adanya pengaruh upwelling terhadap rendahnya SPL di suatu perairan, pada saat terjadinya intensitas upwelling yang tinggi maka sebaran SPL menjadi lebih rendah dari kondisi yang normal pada perairan tersebut, sehingga dapat dikatakan bahwa upwelling berdampak terhadap penurunan SPL. Ketika upwelling terjadi konsentrasi klorofil-a tidak secara langsung meningkat tapi memerlukan jeda beberapa saat sebelum terjadinya peningkatan konsentrasi klorofil-a. Hal ini terjadi karena pada saat terjadi upwelling terjadi pengkayaan nutrien pada perairan tersebut kemudian baru terjadinya peningkatan konsentrasi klorofil-a sehingga hubungannya dengan CUIx tidak terlalu erat seperti SPL. Pada kedua ini, perairan Selatan Jawa yang memiliki hubungan yang lebih erat dengan CUIx dibandingkan dengan perairan barat Sumatera, hal ini disebabkan karena intensitas upwelling di selatan Jawa lebih intensif dari pada di barat Sumatera.

\section{Sebaran Suhu Permukaan Laut (SPL)}

Penyebaran SPL secara spasial ditunjukkan pada Gambar 5, pada musim barat adanya peningkatan SPL pada perairan selatan Jawa maupun barat Sumatera. Hal ini mengindikasikan bahwa pada musim barat tidak ada indikasi terjadinya upwelling pada kedua perairan tersebut. Pada musim timur adanya indikasi terjadinya upwelling ditandai dengan sebaran SPL rendah dari bagian timur perairan selatan Jawa (Bali dan Jawa Timur) kemudian meluas sampai perairan Barat Sumatera (pulau Pagai Selatan). Bagian timur perairan Selatan Jawa memiliki massa air yang lebih dingin dibandingkan bagian barat perairan selatan Jawa. Dinginnya massa air pada perairan pantai dari pada perairan lepas pantai menunjukkan indikasi terbentuknya upwelling pantai.

Secara temporal penyebaran SPL di daerah penelitian ini ditampilkan pada Gambar 6. Kisaran SPL pada kondisi normal di perairan barat Sumatera berkisar antara $25.68{ }^{\circ} \mathrm{C}-31.44{ }^{\circ} \mathrm{C}$, sedangkan selatan Jawa $24.85-31.03{ }^{\circ} \mathrm{C}$. Tahun 2006 (bulan September) ketika terjadi upwelling dengan intensitas yang tinggi maka hal ini berdampak pada penurunan SPL yang mencapai 24.85 (selatan Jawa) dan 25.68 (barat Sumatera), yang juga dipengaruhi oleh terjadi fenomena IODM positif. Susanto et al. (2006) menyatakan bahwa intensitas angin muson akan mengakibatkan meningkatnya intensitas upwelling dari bulan Juni-Agustus yang meningkatkan aliran air dingin dari lapisan bawah ke permukaan seiring dengan bertambahnya bulan.

Bulan Maret 2010 terjadinya sebaran SPL yang tinggi di selatan Jawa diduga terkait dengan IODM negatif dan La Nina yang menyebabkan perairan Indonesia termasuk selatan Jawa memiliki SPL yang lebih tinggi dari kondisi normal (Yoga et al. 2014). Sebaran SPL yang tinggi pada bulan Maret 2005 di Barat Sumatera menurut Amri (2012) terjadi karena pengaruh massa air dari Samudera Hindia bagian barat dan Teluk Bengal yang mengisi perairan timur laut Samudera Hindia posisinya melebar dari utara dan barat perairan Barat Sumatera pada kondisi IODM negatif.

\section{Konsentrasi klorofil-a}

Konsentrasi klorofil-a secara spasial disajikan pada Gambar 7, dimana terlihat bahwa pada musim barat tidak adanya indikasi konsentrasi klorofil-a yang meningkat, sedangkan pada musim timur 
terlihat jelas bahwa adanya konsentrasi klorofil-a yang tinggi dari bagian timur periran selatan Jawa sampai ke bagian Barat Sumatera (Kepulauan Mentawai). Peningkatan konsentrasi klorofil-a dan meluasnya daerah sebaran konsentrasi klorofil-a memiliki hubungan yang erat dengan menurunnya SPL di perairan ini selama musim timur.

Gambar 8 menunjukkan konsentrasi klorofil-a secara temporal, dimana konsentrasi klorofil-a perairan Barat
Sumatera berkisar antara 0.09-0.33 mgm ${ }^{3}$, sedangkan selatan Jawa 0.08-0.97 mgm ${ }^{3}$ pada kondisi normal. Kondisi anomali (tahun 2006) terjadi peningkatan klorofil-a di perairan barat Sumatera mencapai 1.44 $\mathrm{mgm}^{-3}$ dan selatan Jawa mencapai 2.66 mgm $^{-3}$. Hendiarti et al. (2004) menjelaskan bahwa peningkatan klorofil-a di Selatan Jawa karena adanya mekanisme upwelling yang makin intensif sehingga meningkatkan kadar nutrien. yang menghasilkan kadar klorofil-a yang tinggi.
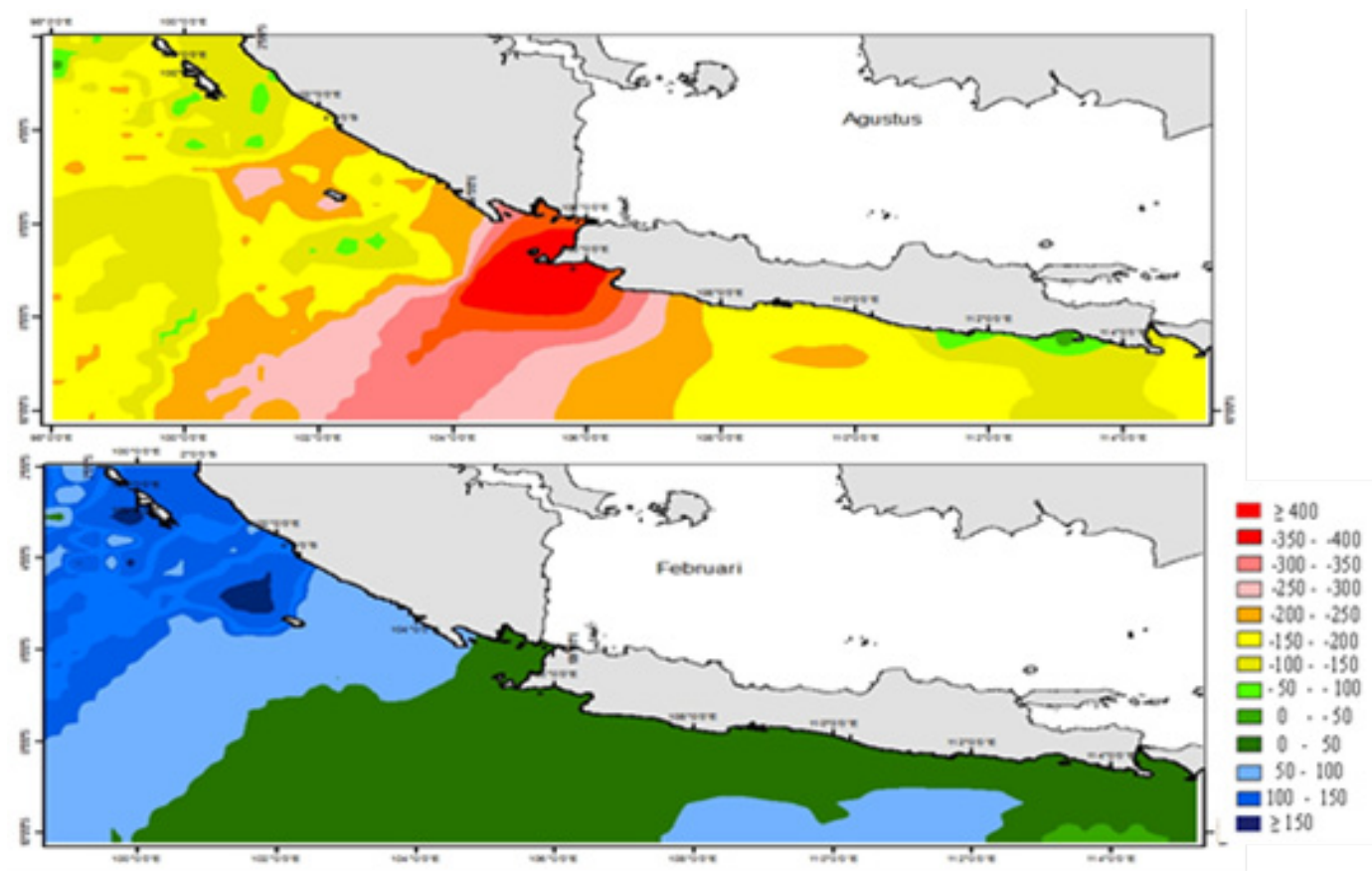

Gambar 2. Sebaran Indeks Upwelling Pantai rata-rata selama tahun 2002 2011 pada musim timur bulan Agustus (atas) dan pada musim barat bulan Februari (bawah)

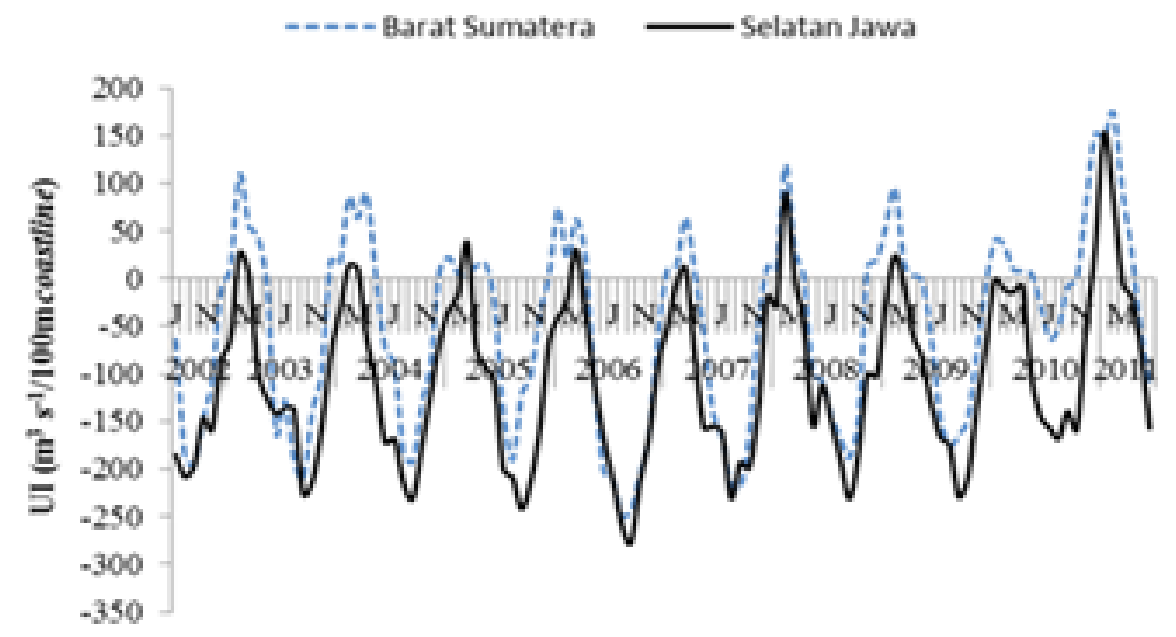

Gambar 3. CUIx di perairan Barat Sumatera dan Selatan Jawa 

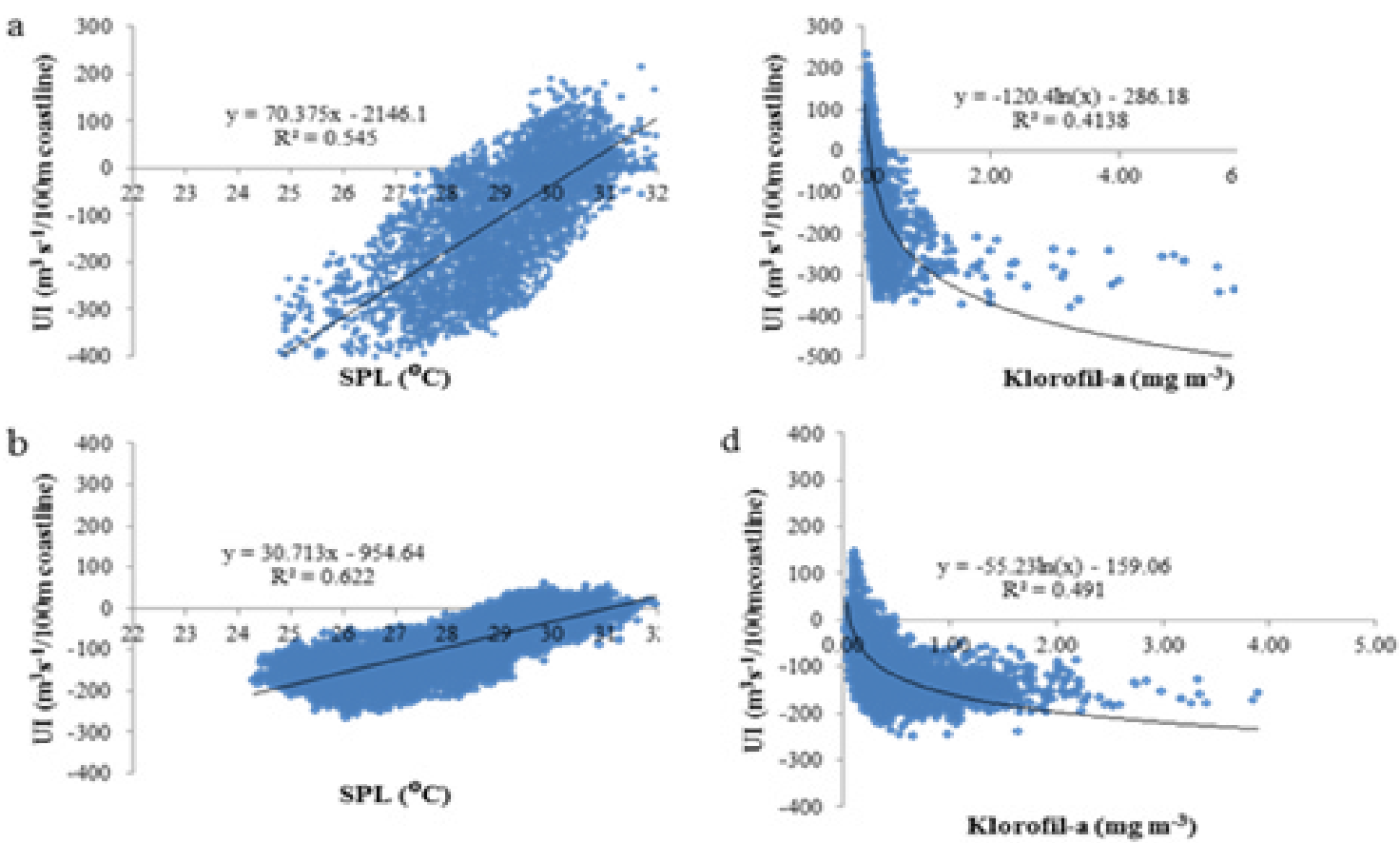

Gambar 4. Hubungan antara CUIx dengan parameter SPL dan klorofil-a rata-rata: (a) SPL dan CUIx Perairan barat Sumatera; (b)SPL dan CUIx selatan Jawa; (c) Chl dan CUIx Barat Sumatera ; (d) Chl dan CUIx Selatan Jawa
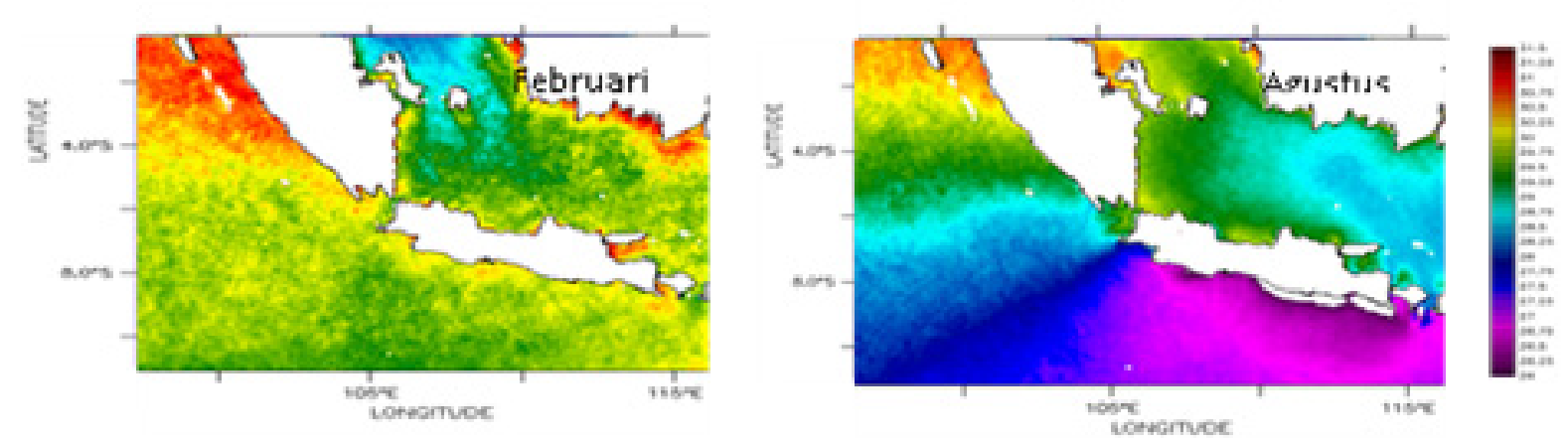

Gambar 5. Gambar 5 Sebaran SPL pada musim barat bulan Februari (kiri) dan musim timur bulan Agustus (kanan)

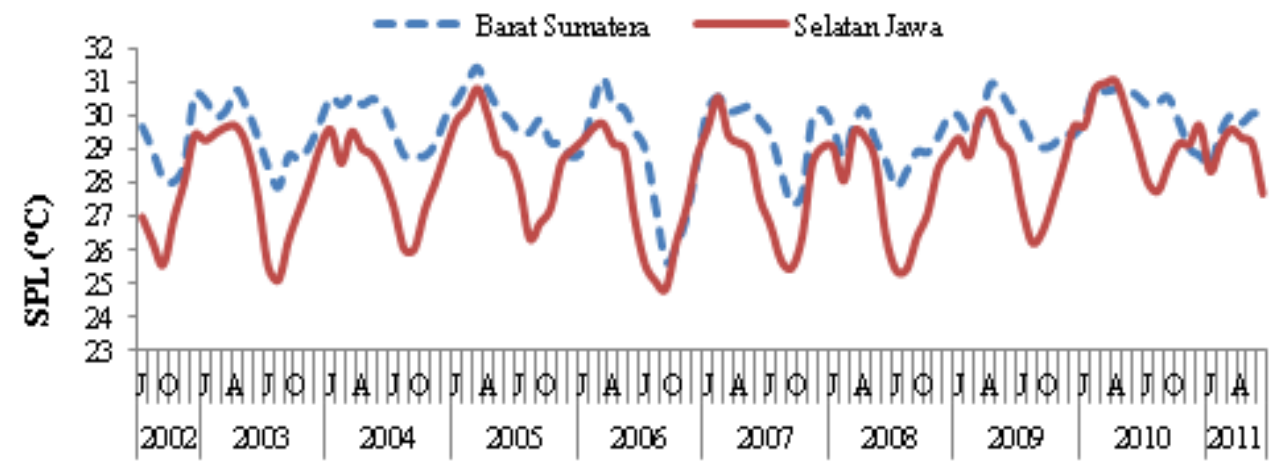

Gambar 6. Sebaran SPL rata-rata selama tahun 2002 - 2011 pada perairan Sumatera dan Selatan Jawa 

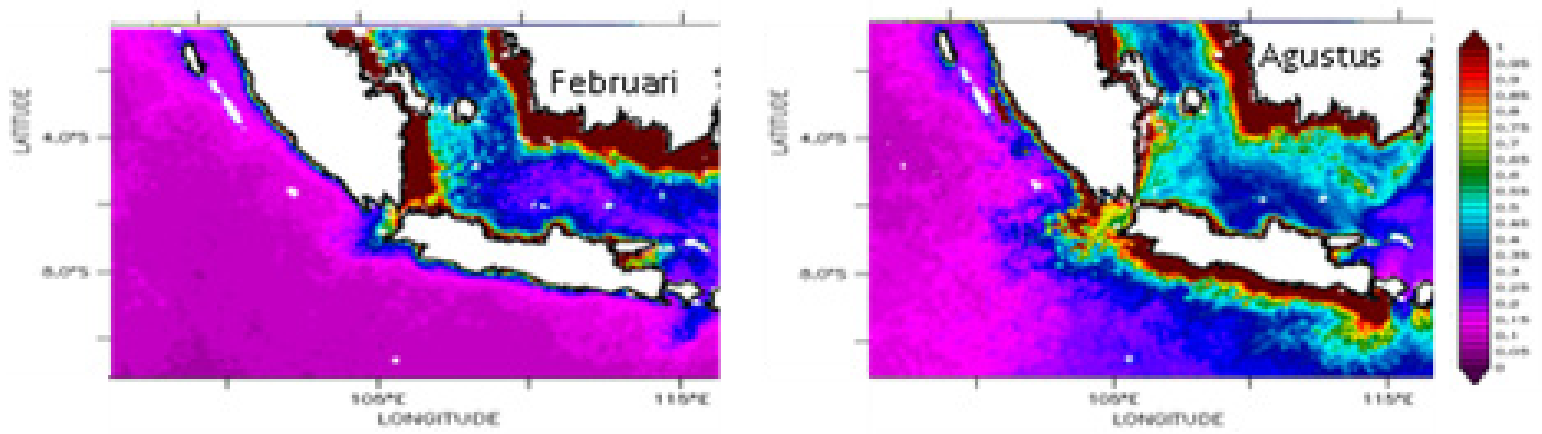

Gambar 7. Konsentrasi klorofil-a pada musim barat bulan Februari (kiri) dan musim timur bulan Agustus (kanan)

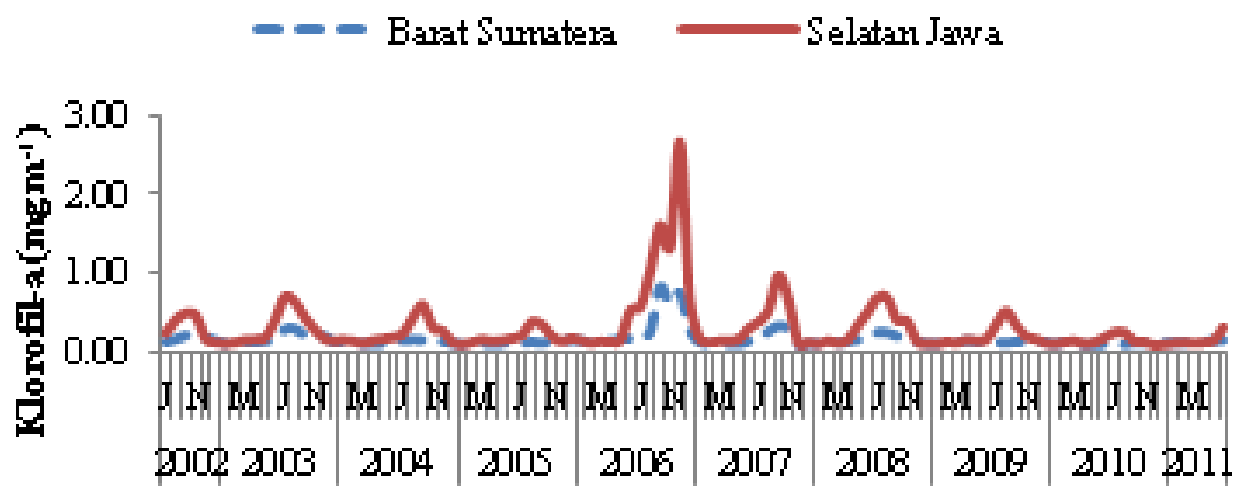

Gambar 8. Konsentrasi klorofil-a Rata-rata selama tahun 2002 - 2011 pada Perairan Barat Sumatera dan Selatan Jawa

\section{KESIMPULAN DAN SARAN}

\section{Kesimpulan}

Hasil penelitian menunjukkan bahwa pada musim timur terjadi upwelling yang ditandai dengan menurunnya SPL dan meningkatnya klorofil-a pada Selatan Jawa $25.10{ }^{\circ} \mathrm{C}$ dan $0.67 \mathrm{mgm}^{-3}$ dan Barat Sumatera $27.30{ }^{\circ} \mathrm{C}$ dan $0.3 \mathrm{mgm}^{-3}$. Selain itu terjadinya kondisi anomali pada tahun 2006 sebagai akibat adanya IODM positif yang berpengaruh pada penurunan SPL 24.98 ${ }^{\circ} \mathrm{C}$ (Selatan Jawa) dan $25.97{ }^{\circ} \mathrm{C}$ (Barat Sumatera) dengan konsentrasi klorofil-a $3.71 \mathrm{mgm}^{-3}$ (Selatan Jawa) dan $1.13 \mathrm{mgm}^{-3}$ (Barat Sumatera).

SPL memiliki hubungan yang sangat kuat dengan CUIx dibandingkan konsentrasi klorofil-a yang dibuktikan dengan koefisien korelasi yang lebih tinggi. Perairan Selatan Jawa memiliki hubungan yang lebih kuat dengan CUIx dari perairan Barat Sumatera.

\section{Saran}

Perlu adanya penelitian lanjutan untuk melihat indeks upwelling dengan menggunakan data insitu angin, SPL dan konsentrasi klorofil-a, sehingga diperoleh hasil yang lebih baik.

\section{DAFTAR PUSTAKA}

Amri K. 2012. Kajian kesuburan perairan pada tiga kondisi moda dwikutub Samudera Hindia (Indian Ocean Dipole Mode) hubungannya dengan hasil tangkapan ikan pelagis di Perairan Barat Sumatera [Disertasi] Bogor: Institut Pertanian Bogor.

Bakun A. 1975. Daily and Weekly Upwelling Indices West Coast of North America. NOAA.

Bowden KF. 1983. Physical Oceanography of Coastal Waters. Chichester: Ellis Horwood Limited Publisher.

Cushing DH. 1975. Marine Ecology and Fisheries. London: Cambridge University Press.

Dahuri R, Rais J, Gintin SP, Sitepu MJ. 1996. Pengelolaan Sumberdaya Wilayah Pesisir dan Lautan Secara Terpadu. Jakarta: PT. Pradanya Paramita. 
Gaol JL. 2003. Kajian karakteristik Oseanografi Samudera Hindia bagian timur dengan menggunakan multi sensor citra satelit dan hubungannya dengan hasil tangkapan tuna mata besar (Thunnus obesus) [Disertasi] Bogor: Institut Pertanian Bogor.

Hendiarti N, Siegel H, Ohde T. 2004. Investigation Of Different Coastal Processes In Indonesian waters using Seawifs data. Deep-Sea Res. II, 51: 85 $-97$

Hutabarat S, Evans SM. 1985. Pengantar Oseanography. Jakarta: Universitas Indonesia Press.

Kemili P, Putri MR. 2012. Pengaruh Durasi dan intensitas upwelling berdasarkan anomali suhu permukaan laut terhadap variabilitas produktivitas primer di Perairan Indonesia. Ilmu dan Teknologi Kelautan Tropis. 4(1):66-79

Kunarso, Ningsih NS, Supangat A. 2005. Karakteristik upwelling di sepanjang Perairan Selatan NTT hingga Barat Sumatra. Ilmu Kelautan UNDIP. Vol. 10

Kunarso, Hadi S, Ningsih NS, Baskoro MS. 2011. Variabilitas suhu dan klorofila-a di daerah upwelling pada variasi kejadian ENSO dan IOD di Perairan Selatan Jawa sampai Timor. Ilmu Kelautan UNDIP. Vol. 16

Nybakken JW. 1988. Biologi Laut Suatu Pendekatan ekologis. Jakarta: Penerbit PT. Gramedia.
Nontji A. 2007. Laut Nusantara. edisi revisi cetakan kelima. Jakarta: Djambatan

Pond S, Pickard GL. 1983. Introductory dynamical oceanography. $2^{\text {nd }}$ edition. Toronto: Pergamon Press.

Stewart RH. 2002. Introduction To Physical Oceanography. Departement of Oceanography Texas A \& M University.

Susanto D, Gordon AL, zheng Q. 2001. upwelling along the coast of Java and Sumatra and its relation to ENSO. Geophysical Research Letter. Vol.28, no 8.

Susanto D, Moore TS, Marra J. 2006. Ocean color variability in Indonesian seas during the SeaWIFS era. $J$ Geochemistry Geophysics Geosystem. 7:1525-2027.

Tubalawony S. 2007. Kajian Klorofil-a-a dan nutrien serta interelasinya dengan dinamika massa air di Perairan Barat Sumatera dan Selatan Jawa Sumbawa [Disertasi]. Bogor: Institut Pertanian Bogor.

Wyrtki K. 1961. Physical Oceanography of Southeast Asian Water. Naga Report vol 2. California: The University of California. Scripps Institution of Oceanography La Jolla.

Yoga RB, Setyono H, Harsono G. 2014. Dinamika upwelling dan downwelling berdasarkan variabilitas suhu permukaan laut dan klorofil-a-a di Perairan Selatan Jawa. Jurnal Oseanografi. 3(1):57-66. 